\title{
Commentary
}

\section{The Effectiveness of Sustainable Indexes Commitment and Trust on Customers' Purchase Decision in Professional Ethics (Iran Khodro Co. in Alborz Province, Iran)}

\author{
Seyyed Hashem Nobari Torkamani ${ }^{1}$, Hamid Torki ${ }^{1}$, Hamid Chegini ${ }^{2}$, \\ ${ }^{1}$ Management Department, Basir Institute, Abyek, Qazvin Iran \\ ${ }^{2}$ mangement Department, ABA Institute, Abyek, Qazvin, Iran
}

Email address:

Hnobari22@yahoo.com (S. H. N. Torkamani), htorki@yahoo.com (H. Torki), hamidchegini26@gmail.com (H. Chegini)

${ }^{*}$ Corresponding author

\section{To cite this article:}

Seyyed Hashem Nobari Torkamani, Hamid Torki, Hamid Chegini. The Effectiveness of Sustainable Indexes Commitment and Trust on Customers' Purchase Decision in Professional Ethics (Iran Khodro Co. in Alborz Province, Iran). International Journal of Sustainability Management and Information Technologies. Vol. 3, No. 3, 2017, pp. 28-33. doi: 10.11648/j.jjsmit.20170303.12

Received: August 10, 2017; Accepted: September 8, 2017; Published: October 26, 2017

\begin{abstract}
Managers and agents working at public sectors need a set of ethical criteria and guidelines in addition to legal criteria which can help them in decision making a, in a world having the characteristics of the third millennium which is saturated in products and experiences so many changes with nonlinear and increasing speed, the only way for the organizations to persist in such intense competition is to gain customer satisfaction. Following social evolutions resulting from high complexity in dividing the social work, professional organizations have played a significant role in setting ethical rules. Social associations lead to emotional attachments and these attachments are effective in ethics. Professional ethics is derived from organizational ethics. Professional ethics are those principles that govern both organizational and managerial functions. Today with broad advancements in management, ethics and human features seem inevitable for managers. Ignoring ethics in interacting with stakeholders causes problems for the organizations and it influences profitability, success and effectiveness of the organization and it questions the legitimacy of the organization. A weak organizational behavior affects the individuals' attitude towards job, management and organization on the whole and it may change the individual and social performance in an organization. As mentioned above, this study seeks to investigate the effect of professional ethics through commitment and trust in customers' purchase decision. The population includes 23 authorized representatives of Iran Khodro Co. in Alborz Province and the sample consisting of 384 subjects was selected based on Morgan table and also random cluster sampling and a tool for collecting data is a standardized questionnaire about professional ethics. This questionnaire contains 19 items and of these, 8 questions are about professional ethics in salesmanship, 4 items are related to trust, 4 items are for commitment and 3 ones are about a decision to purchase and fidelity. To design the questionnaire, for commitment and trust variables, questionnaires designed by Dubisi (Elgase, 1991) including commitment and trust were used and for purchase decision variable, a questionnaire designed by Dubisi (Elgase, Rosemary 1991) was used and Roman and Roise model, 2005, and also Chen and Mao model were used for professional ethics in salesmanship. After collecting the data, we analyzed them by SPSS. Then, we observed that there was a positive relationship between professional ethics and customers' trust and also employees' commitment in the process of decision making to purchase and more profitability in the organization (Iran Khodro Co.)
\end{abstract}

Keywords: Professional Ethics, Trust, Commitment, Customer

\section{Introduction}

In every society, managers and agents working at public sectors need a set of ethical standards and guidelines in addition to legal criteria which can help them in decision making and whenever they doubt an issue, it will remove any doubts and cause movement and dynamics. 
"Ethics is a set of customs in every society and includes those rules that govern the emotions and actions of all members of the society. (According to this, it is obvious that ethics is not a rigid contract but it is based on beliefs. In all behaviors, challenges and movements, we can find a trace of ethics.

When someone does a thing repeatedly, it implies that it has a deep root in his spirit and this is called ethics (in most definitions of ethics, two issues are regarded: the first is that ethics is inner and the second is that in ethics, values are employed. Ethics or morality is a social issue, not an individual one and in fact it is a suitable social medium for special ethical growth or attachment to a certain value. When we add the quality of Islam to ethics, we define a boundary for it which may be different from other boundaries containing other qualities. What is related to the limits of relations and ethics is that in every society, the limits of exploring and analyzing such issue are different from other societies. This is considered a logical movement by which we determine those things a member of the society must do voluntarily as a "correct" thing.

Professional ethics is based on two parameters: 1 . Knowing the culture of the society: Society is formed by a particular culture and in every society; there is a set of ethical principles which follow one specific culture. Thus, we see in some societies that adherence to ethical rules is much more than in other societies. Although humans have common needs and ethical issues, it seems that culture, language and socialhistorical records play a significant role in meeting ethical needs. 2. Every job follows some rules: When these rules incorporate into the culture of a society, they are emphasized by that society. Consequently, some ethical rules are added into that job, for example, the practitioners or lawyers community who follow a specific set of ethical principles.

\section{The Basics of Research}

Harbor and Barout (1987) define ethics as:

"Ethics deals with the manner of behaving in making ethical decisions." Another definition by Biojep (1994) suggests that ethics is a general concept which is used for important ways of studying spiritual life. The concept of professional ethics is derived from ethic.

Most of ethical rules and standards in a culture are different from those in other cultures at different times. In other words, ethical relativism causes a correct thing in one culture to be considered as an incorrect one in another culture and as a result, it may raise discrepancy in values. Ethics at work means recognizing what is right and what is wrong and also it means doing right things and not doing wrong things. Professional ethics is a branch of management knowledge from the advent of social responsibility in 1960s. During this decade, informative social movements exceeded peoples' expectations from the organizations and they concluded that the organizations must use their wide financial facilities and social influence to overcome social problems such as poverty, violence, and protection of the environment, equality of rights, public health and improving the education.
People believe that companies and institutions owe to the country since they get profit using the country' resources and they must try to improve social conditions.

Bernard believed that it is impossible for the organizations to operate without ethics. A leader who does not obey ethical rules loses his influence and cannot persist for a long time. (Bernard, 1983)

On the other hand, there is a close relationship between professional ethics and social responsibility in an organization. It is discussed that job has a significant role, a role that is now more important than in the past. Ethics and social responsibility guarantee the fulfillment of organizational goals And they guarantee those goals in a long time, provided that managers are aware of their social responsibility and ethics. Managers are accountable for their thoughts. And if they are willing to keep their organization, they have to get public satisfaction and fulfill their needs and do their own duties since accepting responsibility establishes public trust which is one of the best social capitals and enhances the effectiveness and acceptability of the organizations, otherwise they themselves are affected by the problems they caused for the society.

\subsection{Professional Ethics}

It is a set of norms and in an organization employees are obliged to obey them to promote the quality of the principles. Ethical systems have two dimensions, fixed and variable ones. Fixed dimensions are beyond time and place and in fact they are taken from ontological attitudes and subjective anthropology. Their nature is eternal and supranational.

Ethical theories indicate that the main origin of ethics is commitment, social responsibility and emotional relations. Emotional relations have a kind of trust, intimacy and commitment and those individuals involved in such relations are obliged to consider the mood of each other. When someone enters an organization, he easily understands that in that organization, all the members behave in a particular way. Although this kind of behavior is called "organizational culture", what is clear is that this culture defines those frameworks which are regarded as the professional ethics of the organization. At first, ethics is formed with all its features taken from the general culture of the society, beliefs, customs and religion, etc. and then, it will appear as the organizational culture. In an organization, members and different classes have minor cultures that distinguish them from the others.

Professional ethics is affected by organizational ethics. Professional ethics are those principles that govern both organizational and managerial affairs.

The term "professional ethics" was first used by Bantam in 831 in his book called "Deontology or Science of Morality". It has not been approved by Academy of France until 748. In the history of statute law in France, the name of the head of the National Center of Practitioners in France, Professor "Perth" is mentioned in the first set of professional ethics of this country in 1946. Professional ethics is defined as a set of positive and negative norms that govern the business and it defines duties and responsibilities of practitioners. 
Deontology has been used many centuries B. C. in various professions. The first legislated law about professional ethics is Hippocratic Oath in ancient Greek in which ethical responsibilities of practitioners were determined.

Elements of professional ethics are: honesty, fairness, loyalty and sense of social responsibility. Professional ethics is a kind of ethical commitment to a job, responsibility and duty. Having morality in a profession results from knowing, wanting, ability and attitude.

\subsection{Parameters of Professional Ethics}

These parameters in relation to customers include showing respect for customers, indiscrimination, better rendering of services, being honest with customers, keeping customers' properties and paying for the damage to the customers' properties, attracting customers through this and in relation to work, they include a sense of responsibility, commitment, being open to criticism, patience, motivation for working, being conscious at work and in relation to society, they include providing the comfort and convenience of customers, resolving a dispute between the customer and employees, continuous learning a skill proportional to modern technology, supporting colleagues, observing social customs, personal neatness and in relation to the employer, they include showing respect for the employer, presenting an accurate report and being accountable to the employer about assignments, etc. In this study, we will specifically discuss trust and commitment.

\subsection{Commitment}

The root of commitment is "responsibility" and it means accepting responsibility and obligation.

In law, commitment is a juridical term by which a person is obliged to transfer or submit properties to the other party, whether the reason for that is matrimony.

Rezayian (1995) suggests that managers agree on the following commitments: 1 . having commitment to the customers or clients. 2. having commitment to the organization. 3. having commitment to one's self. 4. having commitment to the members of the organization. 5. having commitment to the job and duty.

If these are undertaken regularly, they will effectively help management. The manager is the connection between each of these commitments.

\subsection{Trust}

Trust means having confidence in the others' intents and actions and it is a key factor in mutual relationships. Having trust in the organization plays a vital role in fulfilling its goals. Azbern states that lacking intrinsic confidence in the nature of today's business and mass of mutual co-operations have complicated the effectiveness of working relationships. Under uncertain circumstances, if the relationships are clear, keeping effective co-operations will be possible and this happens when mutual trust is obtained. On the whole, psychologists have defined trust as one of the fundamental bases for personal development. Nowadays, scientists of other disciplines, especially business management, describe trust processes as the connection between strategy, participation and pervasive organizational conduct. Trust is a sensitive process and it needs much time to evolve. However, it can be easily disappeared and further access to it is not easy.

Robins Stephen (2003) introduces five dimensions for trust: 1. Honesty: friendship, purity and having truthfulness. 2. Competence: having skills and knowledge necessary in technical affairs and human relations. 3. Stability: reliability, ability to predict, sound judgment when facing different situations. 4. Fidelity: keeping one's secrets and reputation. 5. Truthfulness: exchange of ideas, giving information openly.

\subsection{Purchase Behavior}

Every consumer faces so many purchase decisions and options every day. Most of the firms that study the purchase behavior of consumers try to find appropriate answers about what consumers buy, and the way and number of purchase and also place and reason of purchase. Marketers can do some researches to find answers to these questions. However, obtaining information about the reason for the consumer's or buyer's behavior is not easy since most of the answers to these questions exist in the mind of the consumer. The onset of such studies is stimulus-response model. The consumer's behavior is shaped on this basis that many stimulators and motivational factors along with marketing stimuli enter the black box of the consumer's mind and he shows certain reactions to them.

Marketer wants to know how these stimuli change into different reactions inside the black box of the consumer's mind. The black box consists of two parts: the first part is the personal characteristics of the buyer which have an effect on the ways of depicting these stimuli and reacting to them and the second one is the process of decision making which affects the buyer's behavior.

Proper decision making and establishing effective strategies and techniques for sales and marketing are subject to proper recognition of buyers and consumers. Today, marketing surveyors continuously try to recognize the consumers' behavior and adopt appropriate strategies for higher sales and increasing market share.

Factors effective in decision making are measurable ones such as cost, time, and estimations and so on. There is a general tendency to consider these factors and disregard qualitative ones. 1. Psychological factors: human participation in decision making is clear. Factors such as decision maker's personality, his abilities, experiences, perception, values, desires and his role are of important factors in decision making.

Factors related to the others' agreement, especially those a decision have an effect on them are of important issues in decision making. Regarding these factors reduces the others' resistance to a decision. 2. Cultural factors: The environment has diverse cultural layers which are called regional, national and international or universal cultures. The culture of the organization has also to be considered. These cultures influence our personal or organizational decision in the form of acceptable norms, values and procedures of the society. 


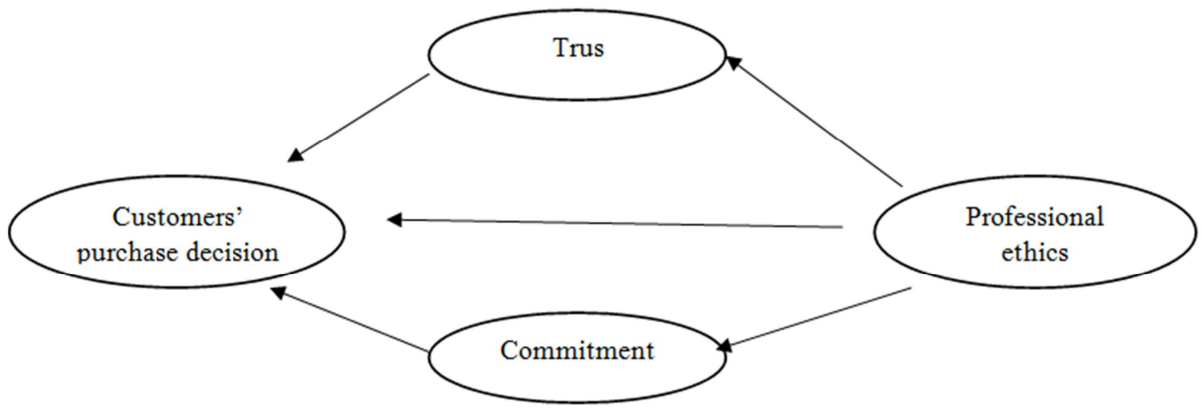

Figure 1. Conceptual Model.

\section{Methods}

The methodology is an applied one regarding objective and the results would be useful for managers, shareholders, investors, creditors, researchers and customers. This study is a descriptive-correlative one. The population includes all the customers of authorized representatives of Iran Khodro Co. in Alborz Province. Since those representatives are scattered in all districts of Alborz Province and it is not possible to refer to the mentioned representatives due to the geographical speed of the underlying district, random cluster sampling was applied in this study as the best method.

Due to the type of this study and also spread of the population and complexity of the sample and in order to get quicker access to the interviews' opinions, the best tool for collecting data in this study is a standardized questionnaire. The questionnaire contains 19 items and of them, 8 items are about professional ethics in sales, 4 items are about trust, 4 items are related to commitment and 3 items are about a decision to purchase and fidelity. To design the questionnaire, for commitment and trust variables, questionnaires designed by Dubisi (Elgase, 1991) including commitment and trust were used and for purchase decision variable, a questionnaire designed by Dubisi (Elgase, Rosemary 1991) was used and Roman and Roise model, 2005, and also Chen and Mao model were used for professional ethics in salesmanship. In the present study, after collecting and converting data into scalar quantities, we analyzed those using statistical charts in SPSS which involves frequency, percentage and response type.

In this study, another objective for descriptive analysis is to study the current traits in the form of some variables such as age, gender, and income which may be effective in identifying existing circumstances and planning.

\section{Result}

Results obtained from analysis are as follows:

Table 1. Frequency Distribution of Responses According to Age.

\begin{tabular}{lll}
\hline Age & Frequency & Percent (\%) \\
\hline $20-30$ & 134 & 35.1 \\
$31-40$ & 172 & 45.0 \\
$41-50$ & 76 & 19.9 \\
Total & 382 & 100 \\
\hline
\end{tabular}

The table above shows that the highest percent, i.e. $45 \%$ of the respondents were between 31-40 and the lowest percent, i.e. $19.9 \%$ of the respondents were between $41-50$.

Table 2. Frequency Distribution of Responses According to Gender.

\begin{tabular}{lll}
\hline Gender & Frequency & Percent $(\%)$ \\
\hline Female & 201 & 52.6 \\
Male & 181 & 47.4 \\
Total & 382 & 100 \\
\hline
\end{tabular}

The table shows that the highest percent, i.e. $52 \%$ of the respondents were female and the lowest percent, i.e. $47.7 \%$, were male.

Table 3. Frequency Distribution of Responses According to Job.

\begin{tabular}{lll}
\hline Job & Frequency & Percent (\%) \\
\hline Clerk & 133 & 34,8 \\
Worker & 204 & 53.4 \\
Self-employed & 45 & 11.8 \\
Total & 382 & 100 \\
\hline
\end{tabular}

The table above indicates that the highest percent, i.e. $53.4 \%$ of the respondents were workers and the lowest percent, i.e. $11.8 \%$ were workers.

Table 4. Frequency Distribution of Responses According to Income.

\begin{tabular}{lll}
\hline Income (toman) & Frequency & Percent (\%) \\
\hline Less than 1 million & 206 & 53.9 \\
1-2 million & 169 & 44.3 \\
More than two million & 7 & 1.8 \\
Total & 382 & 100 \\
\hline
\end{tabular}

The table shows that the highest percent, i.e. $53.9 \%$ of the respondents has an income less than 1 million tomans and the lowest percent, i.e. $1.8 \%$ of the respondents has an income more than two million tomans.

Table 5. Frequency Distribution of Responses According to Education Degree.

\begin{tabular}{lll}
\hline Education degree & Frequency & Percent (\%) \\
\hline Associate's degree & 172 & 45 \\
Bachelor's degree & 19 & 5 \\
Master's degree & 159 & 41.6 \\
PhD & 32 & 8.4 \\
Total & 382 & 100 \\
\hline
\end{tabular}


The table above suggests that the highest percent, i.e. $45 \%$ of the respondents have associate's degree and the lowest percent, i.e. $5 \%$ of the respondents have bachelor's degree.

Table 6. Variance Tolerance and Variance Inflation.

\begin{tabular}{lll}
\hline Variable & Tolerance (\%) & VIF \\
\hline Professional ethics & 82 & 1.42 \\
Trust & 92 & 1.81 \\
Commitment & 81 & 1.96 \\
Purchase decision & 59 & 1.30 \\
\hline
\end{tabular}

One assumption in regression is lacking nonlinearity between independent variables. Variance tolerance and variance inflation control such an assumption. In SPSS, those options have been determined as tolerance and VIF. Tolerance value is between 0 and 1 . There is a value per independent variable. If this value is closer to 1 , this implies that this variable is not linear with the other variables and if it is closer to 0 , it is vice versa. Moreover, VIF shows lack of nonlinearity between independent variables only when it takes a value less than 2 .

Table 7. Regression test Results about the Effect of Professional Ethics on Customers'Purchase Decision.

\begin{tabular}{ll}
\hline Method=inter & \\
\hline Multiple correlation coefficient & 0.593 (a) \\
Determination coefficient & 0.352 \\
Modified determination coefficient & 0.350 \\
Standard deviation & 0.63613 \\
Variance analysis & 206.48 \\
Significance level & 0.000 \\
\hline
\end{tabular}

The results of regression test indicate that regression coefficient with significance level of $\alpha=0.000$ is calculated as $593 \mathrm{R}=0$. Since it is 0.05 smaller than our assumed level, we have enough evidence to reject our null hypothesis, so our null hypothesis is rejected and the main hypothesis is confirmed. Therefore, we conclude that customers' purchase decision is predicted as 0.593 per a variation in one deviation unit of professional ethics.

Table 8. Regression Test Results About the Effect of Professional Ethics on Customers' Trust.

\begin{tabular}{ll}
\hline Method=inter & \\
\hline Multiple correlation coefficient & 0.453 \\
Determination coefficient & 0.205 \\
Modified determination coefficient & 0.203 \\
Standard deviation & 0.38828 \\
Variance analysis & 98.11 \\
Significance level & 0 \\
\hline
\end{tabular}

The results of regression test indicate that regression coefficient with significance level of $\alpha=0.000$ is calculated as $\alpha=0.453 / 0 \mathrm{R}$. Since it is 0.05 smaller than our assumed level, we have enough evidence to reject our null hypothesis, so our null hypothesis is rejected and the main hypothesis is confirmed. Therefore, we conclude that customers' trust is predicted as 0.453 per a variation in one deviation unit of professional ethics.
Table 9. Regression Test Results About the Effect of Professional Ethics on Employees' Commitment.

\begin{tabular}{ll}
\hline Method=inter & \\
\hline Multiple correlation coefficient & 0.564 \\
Determination coefficient & 0.318 \\
Modified determination coefficient & 0.317 \\
Standard deviation & 0.81344 \\
Variance analysis & 177.55 \\
Significance level & 0.000 \\
\hline
\end{tabular}

The results obtained from regression test indicate that regression coefficient with significance level of $\alpha=0.000$ is calculated as $\alpha=0.564 / 0 \mathrm{R}$. Since it is 0.05 smaller than our assumed level, we have enough evidence to reject our null hypothesis, so our null hypothesis is rejected and the main hypothesis is confirmed. Therefore, we conclude that customers' commitment is estimated as 0.564 per a variation in one deviation unit of professional ethics.

Table 10. Regression Test Results about the Effect of Trust on Purchase Decision.

\begin{tabular}{ll}
\hline Method=inter & \\
\hline Multiple correlation coefficient & 0.578 \\
Determination coefficient & 0.334 \\
Modified determination coefficient & 0.332 \\
Standard deviation & 0.67463 \\
Variance analysis & 190.33 \\
Significance level & 0.000 \\
\hline
\end{tabular}

The results obtained from regression test indicate that regression coefficient with significance level of $\alpha=0.000$ is calculated as $\alpha=0.578 / 0 \mathrm{R}$. Since it is 0.05 smaller than our assumed level, we have enough evidence to reject our null hypothesis, so our null hypothesis is rejected and the main hypothesis is confirmed. Therefore, we conclude that customers' purchase decision is estimated as 0.578 per a variation in one deviation unit of trust.

Table 11. Regression Test Results About the Effect of Employees' Commitment on Purchase Decision.

\begin{tabular}{ll}
\hline Method=inter & \\
\hline Multiple correlation coefficient & 0.648 \\
Determination coefficient & 0.419 \\
Modified determination coefficient & 0.418 \\
Standard deviation & 0.38886 \\
Variance analysis & 274.39 \\
Significance level & 0.000 \\
\hline
\end{tabular}

The results obtained from regression test indicate that regression coefficient with significance level of $\alpha=0.000$ is calculated as $\alpha=0.648 / 0 \mathrm{R}$. Since it is 0.05 smaller than our assumed level, we have enough evidence to reject our null hypothesis, so our null hypothesis is rejected and the main hypothesis is confirmed. Therefore, we conclude that customers' purchase decision is estimated as 0.648 per a variation in one deviation unit of trust in employees' commitment. 
Table 12. Hierarchical Regression Test Results.

\begin{tabular}{llllll}
\hline $\begin{array}{l}\text { Independent } \\
\text { variable }\end{array}$ & $\begin{array}{l}\text { Modifier } \\
\text { variable }\end{array}$ & $\begin{array}{l}\text { Dependent } \\
\text { variable }\end{array}$ & F & Sig & Result \\
\hline $\begin{array}{l}\text { Professional } \\
\text { ethics }\end{array}$ & 0.000 & $\begin{array}{l}\text { Purchase } \\
\text { decision }\end{array}$ & 4.89 & 0.000 & Positive \\
$\begin{array}{l}\text { Professional } \\
\text { ethics }\end{array}$ & 0.000 & $\begin{array}{l}\text { Purchase } \\
\text { decision }\end{array}$ & 2.98 & 0.000 & Positive \\
\hline
\end{tabular}

The results of regression test demonstrate that professional ethics has a positive effect on customers' decision in authorized representatives of Iran Khodro Co. through commitment and trust and this relationship has been statistically approved. In other words, an assumption about the positive effect of professional ethics on sales in authorized representatives of Iran Khodro Co. through commitment and trust has been approved.

\section{Conclusion}

Findings show that professional ethics must encourage ethical standards of development to undertake social responsibility since these measures are followed by the increase of employees' ethical attitude. And they also indicate that ethical leadership has a positive relationship with managers' satisfaction and efficiency, subordinates' commitment and their tendency to give a report on the problems to the management. In addition, it is important that most of today's studies deal with evaluating professional ethics.

There is a close relationship between professional ethics and social responsibility in an organization. It is discussed that business has significant effects, those effects that are now more important than in the past.

Ethics and social responsibility guarantee the fulfillment of organizational goals. And they also guarantee those goals in a long time, provided that managers are completely aware of their own social responsibility and behavior in the society. The growth of professional ethics depends on the successful function of professional ethics and also its variability. The more comprehensive the advantages of observing professional ethics are, the higher the commitment to its rules and principles will be. The more logical and effective the applied limitations resulting from professional ethics in the growth of an organization are, the more intense the commitment to it will be. For example, the more successful the professional ethics in establishing ownership in an organization is, the higher the satisfaction of members will be and in committing to its principles, social insistence will dominate individual insistence.

As the present study confirms the mentioned basics, we observed after investigating the data from the questionnaire analysis that professional ethics has a positive effect on the customers' trust and employees' commitment in the process of decision making to purchase and higher profitability in the company (Iran Khodro Co.) as well.

\section{References}

[1] Accumulation, Fatima. Sardari, Butterfly (2006). Ethics, rules and regulations in nursing. Qom.

[2] Brown, m. (2005). Ethical leadership: asocial learning perspective for construct development and testing. p `120.

[3] dynamics of supply ghain network with corporate social responsibility through integrated environment precisionmaking European journal of operational research.

[4] Francisco j, g.rod r, g, and yaiza del m.a.c. (2007) relation between social environ mental responsibility and performance in hotel firms, hospitaling management, jol, pp.

[5] Gramer j-m. (2007). organising corporate social responsibility in international product chains, journal of cleaner production. pp. 1.6.

[6] Maleki, Abbas. ( 2004) Rector for Decision-Making - Process for Resolving Problems - Petrochemical Partners.

[7] Valentine, Sean., and Fleischman, Gary.,(2008) Professional Ethical Standards, Corporate Social Responsibility and The Perceived Role of Ethics an Social Responsibility, journal of Business Ethics 82, pp. 657-666.

[8] Yousefi Nehaleh, Ibrahim (2012) - About Professional Ethics.

[9] Lee, S. H., Lee, T. W. \& Lum, C. F. (2008). The effects of employee services on organizational commitment and intentions to quit. Personnel Review, 37, 2, pp. 222-237.

[10] -Barbalet, J. M, (1994). "Citizenship Rights", in Citizenship Rights: A Critical Concept (Vol. 1), ed. By Bryan. S. Turner and peter Hamilton, London and New York. 